\title{
Effect of hydrotherapy on sleep deficiency among older people in integrated community health services in Pandak I Bantul ${ }^{\dagger}$
}

Original article

Agus Warsenoa,", Anastasia Suci Sukmawatib

aDepartment of Community Health Nursing, Nursing Faculty, Stikes Jenderal Achmad Yani, Yogyakarta 55294, Indonesia

${ }^{b}$ Department of Geriatric Health Nursing, Nursing Faculty, Stikes Jenderal Achmad Yani, Yogyakarta 55294, Indonesia

Received: 4 February 2018; Accepted: 10 May 2018; Published: 20 March 2019

Abstract: Objective: Relaxation technique is a nonpharmacological treatment applied to increase sleep efficiency and the quality of sleep. Hydrotherapy is one of the relaxation techniques and uses warm water to decrease stress and muscle stiffness, as well as to warm the body. The incidence of sleep deficiency among older people in Integrated Community Health Services, Pandak I Bantul, has slightly increased year by year. This research aims to evaluate the effect of hydrotherapy on sleep deprivation among older people.

Methods: The research was a quasi-experimental study with a pre-post test design. Purposive sampling was used to enroll 66 older people from the Integrated Community Health Services, Pandak I Bantul, Yogyakarta, Indonesia, as a sample, and we divided them into two groups: 33 people formed the intervention group, and 33 people comprised the control group. The intervention group did hydrotherapy once a day for a total of 7 days. First, they soaked their feet in warm water for 10 minutes. The water temperature was adjusted according to the body temperature, to approximately $40.0^{\circ} \mathrm{C}-43.0^{\circ} \mathrm{C}$. Then, the intervention group took a bath using warm water. The level of sleep quality was measured using the Pittsburgh Sleep Quality Index (PSQI) questionnaire. Data analysis was done using the Wilcoxon test.

Results: The mean score for sleep quality in the pretest in the intervention group was 9.04 (standard deviation [SD]: 2.57) and the score on the posttest was 42 (SD: 1.43). The mean score for sleep quality in the intervention group was 4.67 , with $P=0.05$. Meanwhile, the research found that the difference between the pretest and posttest scores for quality of sleep in the control group was 0.42 , with $P=0.059$. Wilcoxon analysis found that in the intervention group, there was a significant difference after intervention using hydrotherapy, with $P<0.05$. In the control group, there was no significance difference between the pretest and posttest scores, with $P>0.05$.

Conclusions: According to the results of the present study, it appears that the practice of hydrotherapy is effective in reducing sleep deficiency and hence can be considered an effective method of intervention.

Keywords: hydrotherapy $\bullet$ sleep deficiency $\bullet$ older people $\bullet$ nursing $\bullet$ nursing research literature

(c) Shanxi Medical Periodical Press.

This project was supported by the Center of Research and Community Services (PPPM), Stikes Jenderal Achmad Yani, Yogyakarta (No. SPK/039/STIKES/NI/2016).

How to cite this article: Warseno A, Sukmawati AS. The effect of hydrotherapy on sleep deficiency among older people in integrated community health services Pandak i Bantul. Front Nurs. 2019; 1: xX-XX.

* Corresponding author.

E-mail: gusmotivation@gmail.com (A. Warseno).

¿ Open Access. ๑ 2019 Agus Warseno and Anastasia Suci Sukmawati, published by Sciendo. (c) BY-NC-ND This work is licensed under the Creative Commons Attribution NonCommercial-NoDerivatives 4.0 License. 


\section{Introduction}

The proportion of aging population is increasing rapidly year by year, and the deep influence of this phenomenon on the economic and social conditions has been studied using multilateral approaches, such as social, physical, and psychological aspects. Data from the Central Bureau of Statistics show that the number of aged persons in Yogyakarta has increased from 492,200 in 2015 to 505,100 in 2016. ${ }^{1}$ Changes in the sleep pattern are experienced by older people. Bundlie $^{2}$ states that there are age-related changes in sleep, namely, increased sleep latency, reduced sleep efficiency, increased nocturnal awakening, increased early morning awakening, and increased daytime sleepiness. Sleep quality is essential for older people's well-being and health. Sleep quality in older people can be influenced by environment, pain, ${ }^{3}$ lifestyle, ${ }^{3}$ diet, ${ }^{4}$ psychological condition, ${ }^{4}$ treatment, and cognitive disorders. ${ }^{2,5}$

Relaxation technique is a nonpharmacological treatment that is applied to increase sleep efficiency and improve the quality of sleep. Hydrotherapy, a relaxation technique that uses warm water, can decrease stress, ${ }^{6}$ muscle stiffness, ${ }^{2,5}$ and pain, in addition to warming the body. ${ }^{7,5,8}$ The prevalence of sleep deprivation among older people in the Integrated Community Health Center, Pandak I Bantul, was found to slightly increase year by year. There is no previous study on water treatment for older people with sleep disorder in Bantul, Yogyakarta, Indonesia. This research aims to evaluate the effect of hydrotherapy on sleep deprivation among older people in the Integrated Community Health Center, Pandak I Bantul, Yogyakarta, Indonesia.

\section{Methods}

\subsection{Protocol and registration}

The research was conducted at the Integrated Community Health Center, Pandak I Bantul, Yogyakarta. The subjects were 66 older people with sleep disorder. The quality of sleep was measured using the Pittsburgh Sleep Quality Index (PSQI). The PSQI questionnaire was modified by Herlina. ${ }^{4}$ The PQSI modification had validity and reliability. The $r$ score was $0.528-0.934$, and Cronbach's alpha score was $0.889 .{ }^{7}$ The PSQI contains 15 questions with seven dimensions: subjective sleep quality, sleep latency, duration of sleep, sleep efficiency, sleep disturbance, use of medicines, and daytime sleepiness. Respondents were divided into an intervention group receiving hydrotherapy and a control group receiving no treatment; 33 people were included in each group.

\subsection{Procedure}

After choosing the intervention group, the PSQI questionnaire was administered to the participants. The intervention group did hydrotherapy once a day for a total of 7 days. First, they soaked their feet in warm water for 10 minutes. The water temperature was adjusted according to the body temperature, to approximately $40.0^{\circ} \mathrm{C}-43.0^{\circ} \mathrm{C}$. Then, they took a bath with warm water. The hydrotherapy was performed in the afternoon for all patients. After 7 days of hydrotherapy, the questionnaires were given again to the participants. The lowest score in this questionnaire is zero and the highest score is 21 . A score of zero shows better sleep quality, and the number 21 shows the worst quality of sleep. The quality of sleep is categorized as good if the PSQI score is $\leq 5$ and as poor if the PSQI score is $>5$. The control group did not receive hydrotherapy but participated in regular activities.

\subsection{Statistical analysis}

Wilcoxon analysis was used to determine the difference between the intervention and control groups in terms of the effect of hydrotherapy treatment. ${ }^{9}$

\section{Results}

The data showed that the difference between the pretest and posttest scores for quality of sleep in the control group (0.42) with $P=0.059$, which showed no significance. In addition, the research found that the mean pretest score for sleep quality in the intervention group was as high as 9.09 (SD: 2.57) and the posttest score was 4.42 (SD: 1.43). The mean score of the difference in sleep quality in the intervention group was 4.67 . There was a significant difference in sleep quality before and after intervention using hydrotherapy, with $P<0.05$.

Table 1 shows that before intervention, the respondents in the intervention group had poor sleep quality, with mean score $=9.09$. After intervention, the mean score was 4.42. Meanwhile, the control group shows mean sleep quality scores as follows: pretest score was 7.51 , and posttest score was 7.09.

\begin{tabular}{lccc}
\hline Sleep quality index & Mean & SD & Min-max \\
\hline \hline Intervention group & & & \\
Pretest & 9.09 & 2.57 & $6-15$ \\
Posttest & 4.42 & 1.43 & $2-8$ \\
Control group & & & \\
Pretest & 7.51 & 2.00 & $6-14$ \\
Posttest & 7.09 & 1.62 & $4-11$ \\
\hline
\end{tabular}

Table 1. Pretest and posttest sleep quality indexes in the intervention and control groups $(n=33)$. 


\begin{tabular}{|c|c|c|c|}
\hline Sleep quality index & Mean & $\mathrm{SD}$ & Min-max \\
\hline \multicolumn{4}{|c|}{ K1: Subjective sleep quality } \\
\hline Pretest & 1.39 & 0.49 & $1-2$ \\
\hline Posttest & 1.00 & 0.35 & $0-2$ \\
\hline \multicolumn{4}{|l|}{ K2: Sleep latency } \\
\hline Pretest & 2.66 & 0.64 & $1-3$ \\
\hline Posttest & 0.75 & 0.75 & $0-3$ \\
\hline \multicolumn{4}{|l|}{ K3: Duration of sleep } \\
\hline Pretest & 0.93 & 0.78 & $0-2$ \\
\hline Posttest & 0,54 & 0.61 & $0-2$ \\
\hline \multicolumn{4}{|l|}{ K4: Sleep efficiency } \\
\hline Pretest & 0.63 & 0.69 & $0-2$ \\
\hline Posttest & 0.03 & 0.17 & $0-1$ \\
\hline \multicolumn{4}{|l|}{ K5: Sleep disturbance } \\
\hline Pretest & 1.72 & 0.62 & $1-3$ \\
\hline Posttest & 1.30 & 0,58 & $0-2$ \\
\hline \multicolumn{4}{|l|}{ K6: Use of medicines } \\
\hline Pretest & 0.39 & 0.74 & $0-2$ \\
\hline Posttest & 0.00 & 0.00 & $0-0$ \\
\hline \multicolumn{4}{|c|}{ K7: Daytime sleepiness } \\
\hline Pretest & 1.33 & 0.64 & $0-3$ \\
\hline Posttest & 0.78 & 0.82 & $0-2$ \\
\hline
\end{tabular}

Table 2. Sleep quality in the intervention group $(n=33)$.

\begin{tabular}{|c|c|c|c|}
\hline Sleep quality index & Mean & SD & Min-max \\
\hline \multicolumn{4}{|c|}{ K1: Subjective sleep quality } \\
\hline Pretest & 1.15 & 0.44 & $0-2$ \\
\hline Posttest & 1.12 & 0.41 & $0-2$ \\
\hline \multicolumn{4}{|l|}{ K2: Sleep latency } \\
\hline Pretest & 1.30 & 0.88 & $0-3$ \\
\hline Posttest & 0.93 & 0.74 & $0-3$ \\
\hline \multicolumn{4}{|l|}{ K3: Duration of sleep } \\
\hline Pretest & 1.21 & 0.89 & $0-3$ \\
\hline Posttest & 1.21 & 0.81 & $0-3$ \\
\hline \multicolumn{4}{|l|}{ K4: Sleep efficiency } \\
\hline Pretest & 1.00 & 0.86 & $0-3$ \\
\hline Posttest & 1.03 & 0.88 & $0-3$ \\
\hline \multicolumn{4}{|l|}{ K5: Sleep disturbance } \\
\hline Pretest & 1.36 & 0.54 & $0-2$ \\
\hline Posttest & 1.30 & 0.58 & $0-2$ \\
\hline \multicolumn{4}{|l|}{ K6: Use of medicines } \\
\hline Pretest & 0.42 & 0.50 & $0-1$ \\
\hline Posttest & 0.42 & 0.50 & $0-1$ \\
\hline \multicolumn{4}{|c|}{ K7: Daytime sleepiness } \\
\hline Pretest & 1.00 & 0.82 & $0-2$ \\
\hline Posttest & 0.93 & 0.78 & $0-2$ \\
\hline
\end{tabular}

Table 3. Sleep quality in the control group $(n=33)$.

\begin{tabular}{lllllll}
\hline & Mean & SD & \multicolumn{2}{c}{ Difference } & \multirow{2}{*}{$P$} \\
& & & & Mean & SD & \\
\hline \hline $\begin{array}{l}\text { Intervention group } \\
\quad \text { Pretest }\end{array}$ & 9.09 & 2.57 & 4.67 & 1.14 & 0.000 \\
$\quad$ Posttest & 4.42 & 1.43 & & & \\
Control group & & & & & \\
$\quad$ Pretest & 7.51 & 2.00 & 0.42 & 0.48 & 0.059 \\
Posttest & 7.09 & 1.62 & & & \\
\hline
\end{tabular}

Table 4. The effect of hydrotherapy on sleep quality in the intervention and control groups (pre-post test design) $(n=33)$.

Data in Table 2 show that the mean score for each component of sleep quality index in the intervention group was decreased after hydrotherapy treatment (posttest result).

The most noticeable change noted in Table 2 is that the use of medicines by the elderly in the intervention group decreased extremely, from a mean score of 0.39 to mean score of 0.00 (Table 3 ).

Table 4 shows a significant result in the intervention group, with $P=0.000(P<0.05)$. The mean score for sleep quality index on the pretest was 9.09 (SD: 2.57), while the posttest mean score was 4.42 (SD: 1.43), with difference in the score being as high as 4.67. The difference between the pretest and posttest scores in the control group was 0.42 . However, it showed no significant difference $(P=0.059)$.

\section{Discussion}

Hydrotherapy is the external or internal use of water, in the form of ice or warm water, at various temperatures and pressures, for various durations, and applied at different sites, for promotion of health or for treatment of various diseases. ${ }^{5}$ Hydrotherapy can improve blood circulation by expanding blood vessels. Analysis of the components of sleep quality in the intervention group shows significant difference before and after intervention: subjective sleep quality, sleep latency, sleep duration, sleep efficiency, sleep disturbance, use of medicines, and daytime sleepiness. Hydrotherapy affects the level of serotonin hormone and makes people more relaxed, reducing the sleep deprivation of people as a result. ${ }^{5}$ From the data, it was found that the sleep disorder decreased after hydrotherapy. Low score of sleep quality is an indicator of good sleep quality; therefore, the data obtained from the present study show that hydrotherapy can increase the quality of sleep among older people.

According to the findings of the present study, there is a significant difference in the sleep quality among older people before and after the intervention using 
hydrotherapy. It shows that hydrotherapy treatment is effective in reducing sleep deficiency among older people. A previous study also found that the quality of life was increased and the depression level was decreased among elderly women who received hydrotherapy treatment. ${ }^{10}$ Another study also found that sleep quality was increased after hydrotherapy intervention (indoor warm pool) among older people with fibromyalgia $(P=0.0001){ }^{8}$

Overall, the results of the study show that hydrotherapy is effective in reduction of sleep deficiency. Therefore, hydrotherapy treatment is recommended because it is effective in reducing sleep disorders among the elderly.

\section{Conclusions}

According to the results of the present study, it appears that the hydrotherapy practice is effective in reduction

\section{References}

1. Central Bureau of Statistics. Population projection by age group and sex in D.I. Yogyakarta (x1000). 2017;2015-2022. (in Indonesian).

2. Chaurasia G, Patil E, Dighe S. A review on therapeutic aspects of hydrotherapy. Int $J$ Pharm Sci Res. 2015;6:2713-2722.

3. Haghayeghi M, Kalani N, Nikseresht $A$. The effect of eight weeks of hydrotherapy on life quality and depression in elderly women over 50 years in Jahrom city in Iran. IIOAB J. 2016;7:588-592.

4. Herlina. The effect of progressive relaxation muscle on quality of sleep among older people in Nengahan Trimurti Srandakan Bantul. Yogyakarta: Stikes Jenderal Achmad Yani Yogyakarta. 2016 (In Indonesian).

5. Kasron K, Susilawati S. The effect of progressive muscle relaxation on sleep quality in patients with hypertension in South Cilacap City. Nurscope: of sleep disorders among older people and can be considered as an effective intervention method. Further studies are required to find the mechanism of hydrotherapy and its use in other conditions, using larger sample sizes.

\section{Acknowledgments}

The authors wish to thank the elderly in the community who participated in this study. The authors would like to express gratitude to all who have given generously of their time to edit this paper.

\section{Conflicts of interest}

All contributing authors declare no conflicts of interest. This research received no grant from any funding agency in the public, commercial, or not-for-profit sectors.

J Keperawatan dan Pemikiran IImiah. 2017;3:20-28 (In Indonesian).

6. Meiner SE. Gerontologic nursing fifth edition. Missouri, USA: Elsevier; 2016.

7. Mooventhan A, Nivethitha L. Scientific evidencebased effects of hydrotherapy on various systems of the body. North Am J Med Sci. 2014;6:199-209.

8. Polit DF, Beck TC. Nursing research: generating and assessing evidence for nursing practice, $10^{\text {th }}$ Edition. New York: Wolters Kluwer; 2017.

9. Silva SMOM, Tucano SJP, Kumpel C de Castro AAM, Porto EF. Effect of hydrotherapy on quality of life, functional capacity and sleep quality in patients with fibromyalgia. Rev Bras Reumatol. 2012;52:846-857.

10. Setyowati $S$. The effect of ergonomic gymnastic toward elderly sleep quality in Bantul Yogyakarta. The 2nd University Research Coloquium 2015. 2015:190-200 (In Indonesian). 